\title{
LIBERDADE COMO ESSÊNCIA HUMANA: O PROBLEMA DO SUJEITO NO JOVEM MARX
}

\author{
CRISTIAN ARÃO SILVA DE JESUS ${ }^{1}$
}

RESUMO: Este artigo possui como objetivo analisar a questão da essência humana na obra do jovem Marx. Apresentando uma perspectiva contrária à ideia da existência de um corte epistemológico que cria duas fases absolutamente distintas na filosofia de Marx, pretende-se argumentar que o conceito de essência desenvolvido nos manuscritos de 1844 constitui-se como um importante fundamento para o materialismo histórico. Dessa forma, é oferecida também uma perspectiva diferente do argumento que defende a existência de um antimaterialismo relacionado ao conceito "essência". A interpretação da essência humana como liberdade permite compreender que não há nada de extra-material na definição do ser humano, pois a única característica que sempre acompanhará o homem é a capacidade de se autotransformar através da atividade prática.

PALAVRAS-CHAVE: Essência humana. Sujeito. Liberdade. Jovem Marx.

ABSTRACT: This article aims to analyze the question of human essence in the work of the young Marx. It is argued that the concept of essence developed in the manuscripts of 1844 constitutes an important foundation for historical materialism. In this way, a different perspective is also given to the argument for the existence of an anti-materialism related to the concept "essence". The interpretation of the human essence as freedom allows us to understand that there is nothing extra-material in the definition of the human being, since the only characteristic that will always accompany man is the capacity to develop through practical activity.

KEYWORDS: Human essence. Subject. Freedom. Young Marx.

O problema da essência humana em Marx é uma questão que criou um amplo campo de discussão com diversas posições diferentes. Ao longo da história do marxismo, diversos autores ofereceram contribuições para a interpretação do conceito de ser humano na obra de Marx. A descoberta dos Manuscritos econômico-filosóficos (2010) escritos em 1844, mas só publicados em 1932, pode ser considerada um marco na história desse problema, pois é nessa obra que vimos desenvolvido o conceito "essência humana". Entretanto, alguns autores como Althusser não aceitaram o uso de um conceito oriundo da metafísica numa filosofia materialista. Para resolver esse problema, argumentou que existiria uma ruptura que divide em duas partes a obra de Marx. De um lado, a sua fase jovem, onde ele ainda usava o termo essência e, do outro, a fase madura materialista. Todavia, o conteúdo dos manuscritos, para outros autores, pôde

\footnotetext{
${ }^{1}$ Doutorando em Filosofia pela Universidade Federal da Bahia (UFBA). E-mail: cristian_arao@hotmail.com.
} 
revelar um novo fundamento para o materialismo. Erich Fromm afirma que, embora o termo essência não apareça com muita freqüência na fase mais madura, o significado do conceito permanece na expressão "natureza humana". Herbert Marcuse, por sua vez, argumenta que a compreensão de essência humana como trabalho livre permite conceber a liberdade como definição de ser humano.

A pergunta: “o que é o homem?” é uma questão que remete aos primórdios do pensamento ocidental. Segundo consta, numa narrativa apócrifa, Platão teria afirmado que o homem seria um bípede implume, o que levou Diógenes, o cínico, a depenar uma galinha e apresentá-la como exemplar da espécie humana. A ironia usada nesse ato filosófico mostra a insuficiência da definição platoniana. Posteriormente, Aristóteles encontra na racionalidade (logos) a essência do ser humano, daí surge a definição "animal racional". O estagirita, porém, vai adiante em sua conceituação. Além da razão, existe outro atributo que não é acidental à humanidade: a sociabilidade.

É evidente, pois, que a cidade faz parte das coisas da natureza, que o homem é naturalmente um animal político, destinado a viver em sociedade, e que aquele que, por instinto, e não porque qualquer circunstância o inibe, deixa de fazer parte de uma cidade, é um ser vil ou superior ao homem. Tal indivíduo merece, como disse Homero, a censura cruel de ser um sem família, sem leis, sem lar. Porque ele é ávido de combates, e, como as aves de rapina, incapaz de se submeter a qualquer obediência. Claramente se compreende a razão de ser o homem um animal sociável em grau mais elevado que as abelhas e todos os outros animais que vivem reunidos. A natureza, dizemos, nada faz em vão. O homem só, entre todos os animais, tem o dom da palavra; a voz é o sinal da dor e do prazer, e é por isso que ela foi também concedida aos outros animais. Estes chegam a experimentar sensações de dor e de prazer, e a se fazer compreender uns aos outros. A palavra, porém, tem por fim fazer compreender o que é útil ou prejudicial, e, em consequência, o que é justo ou injusto. $\mathrm{O}$ que distingue o homem de um modo específico é que ele sabe discernir o bem do mal, o justo do injusto, e assim todos os sentimentos da mesma ordem cuja comunicação constitui precisamente a família do Estado. (ARISTÓTELES, 2010, p. 15).

Portanto, além de ser um animal racional, o homem é também um animal social, membro da cidade (pólis), político por natureza (zoon politikon). Tal noção perdurou durante muito tempo na história da filosofia. Todavia, tudo indica que o atributo da racionalidade foi mais determinante para a constituição da ideia moderna de homem. O nascimento da modernidade filosófica é, em larga medida, marcado pela noção de um sujeito plenamente autônomo e racional. Tal ideia trabalhada por Descartes torna-se um dos pilares de todo o pensamento moderno ocidental. A autoconsciência é, então, a condição primeira no trajeto para alcançar a verdade.

Essa concepção de sujeito como algo racional e controlado, que deve manter as paixões, emoções e todas as influências externas sob controle, constituiu o que foi chamado 
posteriormente de subjetividade moderna. Apesar de filósofos como Malebranche e Espinosa, pertencentes à fase inicial da modernidade filosófica, possuírem perspectivas diferentes a essa questão, o paradigma moderno é, em grande medida, marcado pela posição cartesiana quanto a à questão do sujeito.

Uma das características da filosofia do século XIX é a presença de filósofos que teceram críticas a essa noção de sujeito oferecendo um novo paradigma. Dentre esses, sublinhamos aqui o pensamento de Marx. A empreitada de definir subjetividade na obra de tal pensador é complexa e é algo que impulsiona vários debates há muito tempo. Isso ocorre porque o autor d'O capital (2017) nunca sistematizou a sua posição sobre o tema. Sendo assim, ficou a cargo dos intérpretes a tarefa de tentar definir qual seria a concepção marxista de sujeito.

O caminho mostra-se ainda mais tortuoso quando percebemos que, possivelmente, Marx tenha abordado a questão de maneiras distintas ao longo de sua obra. De acordo com Althusser, a variação de perspectiva é tão grande que existiria um corte epistemológico responsável por criar duas fases absolutamente distintas na obra do mouro. "A partir de 1845, Marx rompe radicalmente com toda teoria que funda a história e a política em uma essência do homem" (ALTHUSSER, 1979, p. 200). Segundo o autor argelino, o conteúdo dos manuscritos de 44, ainda muito influenciado por Hegel e Feuerbach, estaria preso a uma ideia de essência humana metafísica e antimaterialista. Todavia, o ano seguinte seria o ano de nascimento da verdadeira teoria marxista. $\mathrm{O}$ abandono da ideia de essência constituiria, portanto, o fundamento da cisão que permite a criação de uma perspectiva científica e materialista na fase iniciada em 1845 . Somente nessa fase madura, Marx teria rompido com o hegelianismo e, de fato, começado a fazer uma filosofia materialista. Por outro lado, outros importantes intérpretes do marxismo leram os Manuscritos econômico-filosóficos de forma diferente, sem considerá-los como algo distinto das outras obras do autor. De acordo com Erich Fromm:

\footnotetext{
Deve ser notado que este conceito de natureza humana não é, para Marx - como tampouco o era para Hegel -, uma abstração. É a essência do homem - em contraste com as várias formas de sua existência histórica -, e, como falou Marx "a essência do homem não é uma abstração inerente a cada indivíduo per si." Também deve ser afirmado que esta frase de $O$ Capital escrita pelo "velho Marx" revela a continuidade do conceito de essência do homem (Wesen) sobre o qual o jovem Marx escreveu nos Manuscritos Econômicos e Filosóficos. Não mais empregou o termo "essência" posteriormente, por ser abstrato e não-histórico, mas claramente manteve a noção dessa essência em uma versão mais histórica, na diferenciação entre "natureza humana em geral" e "natureza humana modificada" de cada época histórica (FROMM, 1983, pp. 34-35).
}

Um dado importante sobre esse debate é que, de fato, Marx evita usar o termo "essência" nas obras após 1844, contudo faz-se necessário questionar o que essa atitude indica. De acordo 
com os partidários da teoria do corte epistemológico, isso indicaria o abandono da ideia de essência junto com toda teoria trabalhada em sua juventude. Contrário a essa perspectiva, Fromm afirma que, muito embora o termo não seja mais usado, o conteúdo que ele expressa mantém-se vivo de certa forma. Marx teria deixado de usar a expressão "essência", mas, mesmo quando a usava, isso não pretendia indicar uma concepção metafísica. Talvez, para evitar ser lido como um não materialista deixa de usar o termo essência (muito usado pelos metafísicos) e passa a usar a expressão "natureza humana". Porém, se existe uma "natureza humana geral" diferente de uma "natureza humana modificada", deve haver atributos da natureza humana que são atemporais e outra natureza que se modifica com o tempo e as circunstâncias. Sendo assim, essa primeira natureza deve corresponder ao que, em sua juventude, Marx chamou de essência. Contudo, isso não deve indicar que a obra marxiana seja antimaterialista. No sentido oposto, o significado de "essência" para o jovem Marx pode ser uma base para o materialismo. Porém, como seria possível, então, afirmar a existência de uma essência materialista?

Herbert Marcuse, primeiro filósofo a escrever sobre o conteúdo dos Manuscritos econômico-filosóficos, publica um artigo no mesmo ano do lançamento da obra (1932), denominado Novas fontes para a fundamentação do materialismo histórico (interpretação dos recém publicados manuscritos de Marx) ${ }^{2}$, onde explica como o conceito de essência constituise como uma base para o materialismo. Até então os esforços intelectuais de Marcuse direcionavam-se à criação de uma fusão entre fenomenologia e materialismo, que ele denominou de "filosofia concreta". Em 1928, citando Heidegger, antecipa, de certo modo, o conteúdo da clássica máxima sartriana "a existência precede a essência."

O que é propriamente existência e como é possível existência em geral? Após longos desvios viu-se, de novo, que o sentido e essência do homem estão resolvidos no seu concreto ser humano situado: "a substância do homem é... a existência" (p. 117). A Filosofia devolveu-se a sua necessidade originária, trata-se unicamente desta existência, da sua verdade e plenificação (MARCUSE, 1968, p. 73).

Marcuse, até então um jovem doutor marxista e hegeliano, lê Ser e tempo no ano do seu lançamento (1927). No ano seguinte muda-se para Freiburg para estudar com o próprio Heidegger. É nesse ano que publica Contribuições para a compreensão de uma Fenomenologia do Materialismo histórico. Nesse artigo, o autor afirma que a fenomenologia poderia estar aliada ao marxismo. Contudo, após descoberta dos manuscritos de 44, abandona o projeto, pois, para ele, a obra do jovem Marx apresentaria uma nova base filosófica que tornou dispensável a

\footnotetext{
${ }^{2}$ Lançado no Brasil junto com Contribuições para a compreensão de uma fenomenologia do materialismo histórico no livro Materialismo histórico e existência (1968).
} 
contribuição heideggeriana. ${ }^{3}$ Segundo ele, a publicação da obra de juventude de Marx foi um ponto decisivo na história do marxismo e pôde oferecer respostas às lacunas que ele via na obra de Heidegger, pois, segundo ele, existiria um déficit das condições históricas concretas do Dasein

Percebe-se, desse modo, que a busca pela concretude leva Marcuse até Heidegger e depois até Marx. Todavia, não abandona completamente as ideias desenvolvidas durante o seu percurso. Baseado na fenomenologia, afirma que o homem é a sua existência, ou seja, a essência humana é o que o indivíduo faz dela. É a prática humana que define a sua natureza. Ao analisar os manuscritos de 44, Marcuse apresenta uma concepção de sujeito no jovem Marx muito próxima à conclusão que ele havia chegado alguns anos antes com o auxílio da obra de Heidegger. De acordo com ele, a compreensão do trabalho como essência humana presente nos Manuscritos econômico-filosóficos corresponde à capacidade que o homem tem de se autogerar, ou seja, de criar a sua própria natureza. Com a transformação da realidade, a natureza humana também se modifica, pois ela é um reflexo das múltiplas determinações.

Nota-se, portanto, que o termo "essência" no jovem Marx não indica uma série de adjetivos que o ser humano vai manter para toda a existência, não se trata de afirmar que o homem é bom ou mal, mas compreender a essência humana como trabalho é afirmar a capacidade humana de se autocriar, isto é, a liberdade.

Vemos, assim, que Marcuse concorda com Fromm ao afirmar que, embora a expressão essência possa indicar um significado idealista, na obra da juventude de Marx ela expressa o contrário. Contudo, para compreender o trabalho como autorealização do homem, é necessário olhar mais de perto essa questão indo aos manuscritos de 44.

Buscando uma característica que diferencie o homem de outros animais, Marx conclui que o ato de transformar a natureza de forma premeditada é uma exclusividade humana. Muito embora os animais também transformem a natureza, eles só agem de acordo com a necessidade imediata. Por outro lado, o ser humano é capaz de construir de maneira prefigurada.

O engendrar prático de um mundo objetivo, a elaboração da natureza inorgânica é a prova do homem enquanto um ser genérico consciente, isto é, um ser que se relaciona com o gênero enquanto sua própria essência ou [se relaciona] consigo enquanto ser genérico. É verdade que também o animal produz. Constrói para si um ninho, habitações, como a abelha, castor, formiga etc. No entanto, produz apenas aquilo de que necessita imediatamente para si ou sua cria; produz unilateral[mente], enquanto o homem produz universal[mente]; o animal produz mesmo livre da carência física, e

${ }^{3}$ Faz-se necessário mencionar outros fatores que foram preponderantes para o abandono da fenomenologia heideggeriana. A entrada de Heidegger no partido nazista, bem como as dificuldades impostas ao processo de habilitação de Marcuse foram outros motivos que ocasionaram o afastamento. 
só produz a si mesmo, enquanto o homem reproduz a natureza inteira; [no animal,] o seu produto pertence imediatamente ao seu corpo físico, enquanto o homem se defronta livre[mente] com o seu produto. $\mathrm{O}$ animal forma apenas segundo a medida $\mathrm{e}$ a carência da species à qual pertence, enquanto o homem sabe produzir segundo a medida de qualquer species, e sabe considerar, por toda a parte, a medida inerente ao objeto; o homem também forma, por isso, segundo as leis da beleza (MARX, 2010, p. 85).

Tudo indica que permanece em Marx a racionalidade como um traço definidor do homem. A liberdade que o ser humano pode exercer ao criar o produto do seu trabalho é resultado do uso da razão. O que permite que ele possa agir de maneira diferente dos outros animais é justamente a capacidade de prefigurar e considerar sua ação. Assim como em Aristóteles e Descartes, parece que na obra do jovem Marx é também possível encontrar a razão como atributo essencial da humanidade. Porém, a expressão "animal racional" não é suficiente para definir o homem, nem para Aristóteles e nem para Marx. Marx reconhece o fato do ser humano ser o único capaz de prefigurar sua transformação da natureza, mas vai além. Percebe que ao intervir no seu meio, o homem altera também a si próprio. Dessa forma, a maneira como ele trabalha, isto é, transforma o seu ambiente, o modifica também.

\footnotetext{
Pois primeiramente o trabalho, a atividade vital, a vida produtiva mesma aparece ao homem apenas como um meio para a satisfação de uma carência, a necessidade de manutenção da existência física. A vida produtiva é, porém, a vida genérica. É a vida engendradora de vida. No modo (Art) da atividade vital encontra-se o caráter inteiro de uma species, seu caráter genérico, e a atividade consciente livre é o caráter genérico do homem. A vida mesma aparece só como meio de vida.

O animal é imediatamente um com sua atividade vital. Não se distingue dela. É ela. O homem faz da sua atividade vital mesma um objeto de sua vontade e da sua consciência. Ele tem atividade vital consciente. (MARX, 2010 p. 84).
}

Visto que o trabalho (atividade produtiva) engendra a vida e que no ser humano essa atividade vital é consciente, o homem tem, então, o potencial de autoengendrar-se. Pode-se afirmar, portanto, que a essência humana é a capacidade de modificar a sua própria natureza. Em outras palavras, é a liberdade, pois não há nada que defina o homem a não ser o poder de criar o seu ser. Entretanto, o ato de autoengendrar não é uma atividade racional fruto de pessoas que analisam friamente as alternativas e decidem a melhor escolha. Em $O 18$ de brumário de Louis Bonaparte (2011) vemos que "Os homens fazem a sua própria história; contudo, não a fazem de livre e espontânea vontade, pois não são eles quem escolhem as circunstâncias sob as quais ela é feita, mas estas lhes foram transmitidas assim como se encontram” (Marx, 2011, p. 25). Diferentemente da ideia cartesiana de sujeito, onde a res cogitans é independente e autônoma, capaz de decidir de maneira puramente racional, na perspectiva marxista o homem sempre responde de acordo as determinações do seu tempo e lugar. Marx percebe que o 
movimento da história é causado pela ação humana, mas esse ser humano que move o processo é um indivíduo inserido em certo contexto. Portanto, o ser humano é capaz de transformar a si mesmo e o seu meio, mas o faz de acordo com as limitações e possibilidades da sua situação. Dessa forma, a maneira como a sociedade se organiza pode desvelar ou obnubilar a capacidade de transformação do homem.

O capitalismo surge, na análise de Marx, como o sistema responsável por criar um modo de vida que impede a realização da essência humana, isto é, da capacidade de autoengendrar-se. Isso acontece devido à organização do trabalho. Sob o capitalismo, não é o produtor quem decide o quê ou quanto produzir, pois precisa vender sua força de trabalho para sobreviver. $O$ trabalhador torna-se, então, mais uma peça na engrenagem da produção e o produto do trabalho humano surge como algo estranho àquele que o produziu.

\footnotetext{
Este fato nada mais exprime senão: o objeto que o trabalho produz, o seu produto, se lhe defronta como um ser estranho, como um poder independente do produtor. O produto do trabalho é o trabalho que se fixou num objeto, fez-se coisal (Sachlich), é a objetivação (Vergegenständlichung) do trabalho. A efetivação (Verwirklichung) do trabalho é a sua objetivação. Esta efetivação do trabalho aparece ao estado nacionaleconômico como desefetivação (Entwirklichung) do trabalhador, a objetivação como perda do objeto e servidão ao objeto, a apropriação como estranhamento (Entfremdung), como alienação (Entäusserung) (MARX, 2010, p. 80).
}

Como o ato de trabalhar torna-se ato de obedecer, o homem sofre uma perda no caráter de consciência e liberdade que fazia parte do conceito de trabalho e que o diferenciava dos outros animais. Dessa forma, o homem tem sua essência ferida, perde sua humanidade. Em nome do aumento do lucro e diminuição dos gastos, a divisão do trabalho faz com que aqueles que estejam na linha de produção percam-se no processo, reduzindo suas funções intelectuais e motoras para o foco da realização de sua tarefa diária. Eles tornam-se, então, mercadorias.

\footnotetext{
O trabalhador se torna tanto mais pobre quanto mais riqueza produz, quanto mais a sua produção aumenta em poder e extensão. O trabalhador se torna uma mercadoria tão mais barata quanto mais mercadorias cria. Com a valorização do mundo das coisas (Sachenwelt) aumenta em proporção direta a desvalorização do mundo dos homens (Menschenwelt). O trabalho não produz somente mercadorias; ele produz a si mesmo e ao trabalhador como uma mercadoria, e isto na medida em que produz, de fato, mercadorias em geral (MARX, 2010, p. 80).
}

Dessa forma, esse processo de estranhamento é o que faz com que ocorra uma alienação da essência humana. Muito embora o homem no capitalismo tenha o trabalho como parte essencial da sua vida, não se realiza nele. Não imprime suas características no produto da sua labuta, não o reconhece, o estranha. O indivíduo, então, torna-se um ser brutalizado, 
desumanizado. Se não é no trabalho que ele realiza-se, o que resta é buscar a realização através das características mais primitivas.

\begin{abstract}
Chega-se, por conseguinte, ao resultado de que o homem (o trabalhador) só se sente como ser livre e ativo em suas funções animais, comer, beber e procriar, quando muito ainda habitação, adornos, etc., e em suas funções humanas só se sente como animal. $\mathrm{O}$ animal se torna humano e o humano, animal. Comer, beber, procriar, etc., são também, é verdade, funções genuinamente humanas. Porém, na abstração que as separa da esfera restante da atividade humana, e faz delas finalidades últimas e exclusivas, são funções animais (MARX, 2010, p. 83).
\end{abstract}

Acompanha o déficit da liberdade de produzir a diminuição das faculdades abstratas, de projetar e inventar. Com a divisão do trabalho, uns ficam responsáveis por prefigurar o que é feito e outros por realizar o projeto. Quanto aos últimos, é fácil compreender como a alienação funciona, pois eles são encarregados somente de cumprir as tarefas que lhes foram postas. Contudo, o primeiro grupo também não está imune à alienação. Raramente um projeto é pensado com ampla liberdade. Aqueles que pensam sobre como e o que produzir o fazem seguindo orientações específicas, seja do patrão, seja do mercado. Isso quer dizer que mesmo os responsáveis pelo trabalho intelectual devem subordinar sua capacidade cognitiva às leis do mercado.

\footnotetext{
Partindo desta "alienação" do trabalhador e do trabalho, surgiu uma total "desconcretização", a partir da concretização de todas as "forças essenciais"; o mundo objetivo não é mais "autêntica propriedade humana", apropriada em "livre atividade" e campo da livre afirmação e afirmação de toda natureza humana, e sim um mundo de coisas possuídas, utilizáveis e trocáveis na propriedade privada, a cujas próprias leis inalteráveis o homem está submisso - em poucas palavras: um universal "domínio da matéria morta sobre os homens (MARCUSE, 1968, p. 108).
}

Portanto, o mundo deixa de ser algo aberto, que permite diferentes meios de intervenção e, assim, diferentes meios de vida. Surge a preponderância de um único meio de vida. A lógica da economia torna-se o padrão de vida a ser seguido e esse padrão gera um estado de sofrimento. A ruptura na relação do trabalhador com o trabalho e a afirmação do modo de vida pautado no trabalho estranhado é sentida como uma espécie de mal-estar social. Isso acontece porque o trabalho não é realização, é obrigatório (MARX, 2010, p. 83), é martírio (MARX, 2010, p. 86). Poucas são as pessoas que possuem o privilégio de imprimirem, de fato, seu ser no resultado do seu trabalho (e mesmo essas pessoas devem seguir as mesmas leis que regem a vida compreendida como atividade econômica). De acordo com Marx, o fato das pessoas não se sentirem representadas nos produtos dos seus trabalhos faz com que a atividade laboral seja sinônima de infelicidade, onde o trabalhador sente a morte do seu corpo e espírito (MARX, 2010, pp. 82-83). Pode-se receber a relação entre trabalho e infelicidade, dentre outras formas, analisando como empregamos a palavra "trabalho". É costumeiro atribuir o adjetivo "trabalhoso" às atividades exaustivas, penosas e que, de alguma maneira, ocasionem 
sofrimento. A raiz etimológica da palavra remete a infelicidade. A palavra latina tripalium denomina um instrumento de tortura usado em escravos. O verbo tripaliare expressa, portanto, a ação de torturar alguém sobre o tripalium (Illich, 1976, p. 45). Considerando-se toda essa infelicidade relacionada ao trabalho, talvez seja possível dizer que, sob o capitalismo, o ato de trabalhar não esteja tão distante do ato de se autotorturar. A rotina do trabalhador assemelha-se ao suplício de Sisífo que deve carregar todos os dias a mesma pedra para o cume da montanha, ou de Prometeu, que tem seu fígado (representação da sede das paixões e da energia) devorado por uma águia da alvorada ao crepúsculo. Assim como os personagens mitológicos, o trabalhador também passa seus dias gastando sua energia vital em algo estranho, em um trabalho repetitivo onde ele não se realiza.

De outro modo, a alienação ocasiona também o distanciamento dos próprios seres humanos entre si. Aristóteles já havia afirmado a relevância da vida em sociedade para o ser humano. No mundo grego em geral, o homem não era pensado como isolado da pólis. O caráter gregário esteve durante muito tempo com a humanidade, até o capitalismo surgir. Nos Grundrisse, Marx afirma que "O ser humano só se individualiza pelo processo histórico. Ele aparece originalmente como um ser genérico, ser tribal, animal gregário - ainda que de forma alguma como um zoon politikón em sentido político" (Marx, 2015 p. 658-659). Portanto, ainda que não concorde com a ideia política de Aristóteles, parece haver alguma consonância no sentido de compreender o ser humano como ser social.

O homem é um ser genérico (Gattungswesen), não somente quando prática e teoricamente faz do gênero, tanto do seu próprio quanto do restante das coisas, o seu objeto, mas também - e isto é somente uma outra expressão da mesma coisa - quando se relaciona consigo mesmo como [com] o gênero vivo, presente, quando se relaciona consigo mesmo como [com] um ser universal, [e] por isso livre. (MARX, 2010, pp. 83-84)

Tudo indica que a expressão ser genérico corresponde ao caráter social da vida humana ao “entrelaçamento material de um 'nós' mutuamente reconhecedor” (Holloway, 2003, p. 74), mas, analisando mais detidamente, compreende-se de forma mais profunda o significado do conceito. Giorgio Agamben, em seu primeiro livro, denominado The man without content, analisa a expressão da seguinte forma:

Habitualmente se traduz essa expressão [Gattungswesen] por "ser genérico ou "ser pertencente a uma espécie", no sentido derivado das ciências naturais que as palavras "espécie" e "gênero" têm na linguagem comum. Mas Gattung não significa simplesmente "espécie natural" e isso é provado pelo fato de que Marx considera a qualidade de Gattungswesen precisamente como caráter que distingue os homens dos 
outros animais e a conecta expressamente à práxis, à atividade vital consciente própria do homem, e não à atividade vital dos animais (...)

Dizer que o homem é capaz de ser um gênero, um Gattungswesen, significa que há para o homem um continente original, um princípio que faz com que o os indivíduos humanos não sejam estranhos uns para os outros, mas sejam precisamente humanos, no sentido de que em todo homem está imediatamente e necessariamente presente o gênero inteiro. (AGAMBEN, 1999, pp. 82-83, tradução nossa).

Compreender o ser humano como um ser genérico é, portanto, afirmar que existe uma humanidade, algo que mantém junto os seres humanos. O trabalho alienado cumpre o papel de obnubilar esse reconhecimento entre os do mesmo gênero. É a dissolução do "nós", da ideia de comunidade. Percebe-se, então, que a alienação marca a história da humanidade, transformando o fazer humano em sofrimento e dissolvendo os laços que unem as pessoas, dessa forma criando um modo de vida pautado na labuta e no individualismo. No entanto, se compreendermos a liberdade como essência humana, concluímos também que o trabalho alienado é também obra do homem.

Não é resultado do destino ou da intervenção divina: o fazer humano é o único sujeito, o único que constitui poder. Somos os únicos deuses, os únicos criadores. Nosso problema, como criadores, é que estamos criando nossa própria destruição. Criamos a negação de nossa própria criação. $O$ fazer se nega a si mesmo. A atividade se converte em passividade, o fazer se torna não-fazer. A alienação assinala tanto nossa desumanização como o fato de que a produzimos (HOLLOWAY, 2003, p. 75).

O dilema da liberdade reside no fato de que, dentre diversas possibilidades possíveis, existe também a alternativa de criar e submeter-se a um sistema que retira a liberdade. Todavia, não há como não escolher. A constituição de um sistema que impede o avanço da liberdade é também obra da humanidade. Por mais que a organização social impeça o desenvolvimento da essência humana, não é possível suprimi-la. Se o homem criou a alienação, é capaz também de efetuar uma transformação na realidade que liberte as suas potencialidades. Desse modo, a crítica ao trabalho estranhado não é somente uma questão de economia ou política, mas revela uma dimensão muito maior, acusa uma "catástrofe do ente humano" (MARCUSE, 1968, p. 132). A revolução torna-se, então, a missão a ser realizada para findar a alienação e criar um mundo de autodeterminação. Porém, "Não se trata 'da' missão do homem e sim de uma determinada situação histórica, pois já sabemos que cada realidade humana é uma realidade histórica, que o homem só tem sua "certidão de nascimento na história (...)" (MARCUSE, 1968, p. 138). Dessa forma, percebe-se que não há nenhum propósito preestabelecido para a história humana. Ter a liberdade como sua essência implica justamente nas múltiplas possibilidades de destino.

Sendo assim, conclui-se que Marx, nos manuscritos de 44, propõe a existência de uma essência humana, mas isso não quer dizer que ele assume uma posição antimaterialista. O que 
caracteriza o ser humano não é algo proveniente de fora dele, mas sim o resultado de sua própria ação no mundo. Conceber a liberdade como a essência do homem é, portanto, reconhecer que há um certo vazio. Não há bondade nem maldade eternas em sua natureza, como também não há um destino predefinido. Há somente a capacidade de transformar a realidade e transformar a si mesmo. Contudo, ele não faz isso sozinho e nem de maneira simples e imediata. Diferentemente da subjetividade moderna cartesiana, o sujeito aqui não é somente o cógito, não é um ser independente e capaz de meditar isolando as influências exteriores. Tampouco é um ser completamente determinado pelo meio social. O sujeito, em Marx, perde a soberania absoluta, pois pensa e age a partir do meio em que está inserido, não é considerado indivíduo isolado, mas um ser social. Por esse motivo, surge a necessidade de superação do capitalismo e criação de um sistema onde não exista o trabalho alienado e a essência humana possa se efetivar. Com o trabalho livre, a humanidade poderá, então, criar diferentes formas de vida que não estejam baseadas no sofrimento e na labuta.

\section{REFERÊNCIAS BIBLIOGRÁFICAS}

AGAMBEN, G. The man without content. Redwood City: Stanford university press, 1999.

ALTHUSSER, L. A favor de Marx. Rio de Janeiro: Zahar Editores, 1979.

ARISTÓTELES. A Política. São Paulo: Folha de São Paulo, 2010.

DESCARTES, R. Discurso do método. São Paulo: Nova Cultural, 1988.

FROMM, E. O conceito marxista de homem. Rio De Janeiro: Zahar editores, 1983.

HEIDEGGER, M. Ser e tempo. Petrópolis: Vozes, 2015.

HOLLOWAY, J. Mudar o mundo sem tomar o poder. São Paulo: Viramundo, 2003

ILLICH, I. A convivencialidade. Lisboa: Europa América, 1976.

MARCUSE, H. Materialismo histórico e existência. Rio de Janeiro: Tempo brasileiro, 1968.

MARX, K. Grundrisse: manuscritos econômicos de 1857-1858: esboços da crítica da economia política. São Paulo: Boitempo, 2015. Manuscritos econômico-filosóficos, São Paulo: Boitempo, 2010.

O capital: crítica da economia política: livro I: o processo de produção do capital, São Paulo: Boitempo, 2017. O 18 de brumário de Luis Bonaparte, São Paulo: Boitempo, 2011.

SARTRE, J.P. O ser e o Nada: ensaio de ontologia fenomenológica. Petrópolis: Vozes, 2005. WIGGERSHAUS, R. A escola de Frankfurt: história, desenvolvimento teórico, significação política. São Paulo: Difel, 2002. 